\title{
Determination of Tetracycline and Oxytetracycline Residues in Honey by High Performance Liquid Chromatography
}

\author{
Shaif Mohammed Kasem Saleh ${ }^{1}$, Amer Mohammed Mussaed ${ }^{1}$ and Fadhl Mohammed Al-Hariri ${ }^{2}$ \\ 1. Department of Chemistry, Faculty of Science \& Education, University of Aden, Aden, Yemen \\ 2. National Quality Control Laboratory, Aden, Yemen
}

\begin{abstract}
Honey is being used as a pure natural and as an ingredient in many foods, pharmaceuticals and cosmetics than ever before, so honey testing has become essential to maintain its healthful characteristics and protect public health. Tetracyclines (TCs) are used for the treatment or prevention of American and European foul broad in bee colonies which are caused especially by two species of bacteria-Paenibacillus larvae and Melissococcus pluton. The present study aimed to determine the tetracycline residues in different types of local and imported honey. The reversed-phase high performance liquid chromatography (HPLC) with ultraviolet detection (UV) was used. Tetracycline and oxytetracycline were extracted from honey with $0.01 \mathrm{M}$ sodium succinate buffer. Of the examined samples, $31.25 \%$ and $12.50 \%$ had these oxytetracycline and tetracycline residues, respectively. It was observed that all the samples studied have been reported residues of tetracycline and oxytetracycline more than international standards of maximum residue limit (MRLs).
\end{abstract}

Key words: Honey, antibiotic residues, tetracycline, oxytetracycline, HPLC, Yemen.

\section{Introduction}

Honey is used widely throughout the world. Honey is one of the best natural products in terms of biomedical value and its endless use, and is the greatest natural product as well as food. It contains many active compounds that carry out the functions of antioxidants along with a lot of material that earn human activity body and protect it from several diseases [1, 2]. Recently, the Yemeni markets have been invaded by many works, such as honey imported from Turkish, German and Kashmiri, etc., and due to the high price of Yemeni honey, these types have received great demand among consumer [3]. Studies show that in recent years, honey and other bee products face problems in the growing use of antibiotics and pesticides, which means that honey may become contaminated with residues of antibiotics,

Corresponding author: Shaif Mohammed Kasem Saleh, associate professor, research fields: environmental chemistry and pollution. pesticides and toxic substances, and thus affects the human health and environment. Thus, the need of a lot of research is prompted in order to detect antibiotic residues and pesticides in honey and control them within the limits of these pollutants through the development of legislative specifications [1, 2, 4-10].

Tetracyclines (TCs) are used for the treatment or prevention of American and European foul broad in bee colonies, which are caused especially by two species of bacteria-Paenibacillus larvae and Melissococcus pluton [6, 8-10]. The presence of tetracycline and its degradation products in honey may have harmful effects on consumers, such as possible allergic reactions, liver damage, yellowing of teeth and gastro-intestinal disturbance due to the selective pressure of antibiotics on the micro flora of human gut [9]. The European Union Regulation 396/2005 [11] has recommended zero level tolerance for oxytetracycline residues in honey. According to Regulation (EC) No. 470/2009 [12] and Regulation 
(EU) No. 37/2010 [13] in the European Union, no maximum residue limit (MRL) for tetracycline in honey has been set. This means that the presence of tetracycline residues in honey is not allowed. Despite this decision, some countries have established action limits or tolerated levels for tetracycline in honey. For instance, in Belgium, the action limit for the group of tetracycline has been fixed at $20 \mu \mathrm{g} / \mathrm{kg}$. France applies a nonconformity limit for tetracycline in honey of 15 $\mu \mathrm{g} / \mathrm{kg}$, the reporting limit in Great Britain is $50 \mu \mathrm{g} / \mathrm{kg}$, while the tolerance level in Switzerland is $20 \mu \mathrm{g} / \mathrm{kg}$ [10]. In Japan, base on microbiological research, a value of $0.1 \mathrm{mg} / \mathrm{kg}$ was introduced as the allowed residual quantity of tetracycline in honey [8]. Australia, Indian, American and the US Food and Drug Administration (USFDA) have set MRL for only oxytetracycline in honey at $300 \mathrm{ppb}[4,14,15]$.

The present study aimed to determine tetracycline and oxytetracycline residues in different types of local and imported honey by high performance liquid chromatography (HPLC).

\section{Materials and Methods}

\subsection{Honey Samples}

In this study, there are total seven locally produced honey and nine imported honey were studied. Among seven locally produced honey, four fresh honey were collected from honey bee breeding location (Acacia tortilis and Sidr honey from Dowan in Hadramout; Sider honey from Jardan, Bayhan in Shabwa; Sider honey from Radfan), while the other three samples were collected from commercial markets of the city of Aden (Osaimi sider honey from Sana'a; Soctotra honey from Soctotra; Maraihoney from Abyan).

Nine samples of imported honey included Kashmiri honey imported by Galap (India), pure bees honey from Germany, black forest honey from Germany, tropical plants honey from Thailand, nutrition honey from Australia, Kashmiri honey imported by Saudi Arabia (India), Kashmiri honey imported by Yemen (India), black bean honey from (Egypt) and Bashaori honey from Pakistan, which are randomly from different commercial markets of the city of Aden.

\subsection{Apparatus}

The LC system consisted of Shimadzu VP series (Japan). This was equipped with binary LC-10AD pump, DGU-14A degasser, SLC-10A system controller, CTO-10AS column oven, SIL-10AF auto-injector and SPD-10A UV-VIS detector set at $360 \mathrm{~nm}$ wavelength. The separation was performed on a Nucleosil $100 \mathrm{RP}-18,5 \mu \mathrm{m}$ column, $250 \mathrm{~mm} \times 4.6$ $\mathrm{mm}$ internal diameter (ID) with a guard column (4.6 $\mathrm{mm} \times 7.5 \mathrm{~mm}$ ID) containing same packing material.

The optimal selected mobile phase was $10 \mathrm{mM}$ oxalic acid, acetonitrile and methanol (16:3:2), and the symmetrical non-tailed peaks were obtained. The flow rate was $1 \mathrm{~mL} / \mathrm{min}$, the injection volume was $50 \mu \mathrm{L}$ and the column temperature was $35^{\circ} \mathrm{C}$.

\subsection{Reagents}

Ultra pure water (LC grade) and the solvents methanol and acetonitrile (LC grade), ethanol absolute (reagent grade) were used. The extraction solution was a sodium succinate buffer. A $0.1 \mathrm{M}$ succinic acid solution was prepared and adjusted to right $\mathrm{pH}$ with 5 $\mathrm{M}$ sodium hydroxide. The buffer solution is stable at $4{ }^{\circ} \mathrm{C}$.

\subsection{Calibration}

Under the optimized experimental conditions, there were good linearities found between tetracyclines concentration and peak area responses ranged from $10-50 \mu \mathrm{g} / \mathrm{mL}$ with $r^{2}>0.999$. Method validation results were satisfied with linear regression equations, as shown in Table 1.

\subsection{Analytical Procedure for Honey Samples}

A total of 16 honey samples (weighing $30 \mathrm{~g}$ each) were obtained from local and imported honey. Honey samples were transferred to National Quality Control Laboratory, Aden, under appropriate conditions, and 
Table 1 Validation results of oxytetracycline and tetracycline*.

\begin{tabular}{llll}
\hline Tetracyclines & $\begin{array}{l}\text { Retention time } \\
(\mathrm{min})\end{array}$ & Regression equation & $\begin{array}{l}\text { Correlation coefficient } \\
\left(r^{2}\right)\end{array}$ \\
\hline Oxytetracycline & 4.1 & $y=19,496.8 x+29,605.8$ & 0.9997 \\
Tetracycline & 4.8 & $\mathrm{y}=23,718.8 x+33,353.9$ & 0.9993 \\
\hline
\end{tabular}

${ }^{*}$ Based on three replicates of five concentration in the range of $10-50 \mu \mathrm{g} / \mathrm{mL}$.

then analyzed immediately after preparations.

Tetracycline and oxytetracycline were detected according to Bonta et al. [6], which include sample extraction, clean-up procedure, analytical procedure and method validation.

The honey sample was weighted and dissolved in sodium succinate extraction solution. The solution was stirred and centrifuged at 2,500 rpm for $10 \mathrm{~min}$. The solution was filtered through a $0.45 \mu \mathrm{m}$ nylon chromatographic filter and then injected into the HPLC system. Calibration curves were performed for each tetracycline from standard chromatograms, by plotting concentration against peak area.

\section{Results and Discussion}

The results of tetracycline and oxytetracycline residues analysis of 16 samples of local and imported honey are shown in Table 2.

\subsection{Imported Honey Samples}

Oxytetracycline was detected in most of the imported honey samples. The concentration of oxytetracycline residues was found to be high in the black Forest honey with $13,800 \mu \mathrm{g} / \mathrm{kg}$, followed by Kashmiri honey imported by Yemen (sample 3: $(9,033 \mu \mathrm{g} / \mathrm{kg}$ ), pure bees honey (sample 1: 3,610 $\mu \mathrm{g} / \mathrm{kg}$ ) and Kashmiri honey imported by Saudi Arabia (sample 4: 3,430 $\mu \mathrm{g} / \mathrm{kg}$ ). However, the oxytetracycline residues were higher than the MRL established by European Union Regulations [2, 11-13], and Australia, Indian, American and USFDA [4, 14, 15]. The rest of the samples did not show for oxytetracycline residues in honey or probably less than the limits of detection device. Tetracycline residues were detected less in the imported honey samples. The study showed the presence of residues of the antibiotic tetracycline only in the Bashaori honey from Pakistan with 2,330 $\mu \mathrm{g} / \mathrm{kg}$. The tetracycline residues were higher than the MRL for international specifications $[4,14]$.

\subsection{Locally Produced Honey}

The concentration of oxytetracycline residues was found $7,140 \mu \mathrm{g} / \mathrm{kg}$ in the Sider honey of Jardan. Tetracycline residues were detected less in the honey imported samples. The study showed the presence of residues of the antibiotic tetracycline only in the Marai honey of Lowder with $2,850 \mu \mathrm{g} / \mathrm{kg}$. However, the oxytetracycline and tetracycline residues were higher than the MRL for international specifications $[4,6,11$, $14,15]$.

Tetracycline and oxytetracycline residue values of honey samples in the present study are considerable compared with other country honey samples. And the results of their comparison are shown in Tables 3 and 4 .

As shown in Table 3, the range of oxytetracycline residue in contamination samples of current study was between $3,430 \mu \mathrm{g} / \mathrm{kg}$ and $13,800 \mu \mathrm{g} / \mathrm{kg}$, lower than those obtained by Narin and Supaporn from Thailand $(60,150-106,900 \mu \mathrm{g} / \mathrm{kg})$ [8] and higher than the results of applied studies in Greece [5], Iran [1], Pakistan [16] and India $[2,7]$.

The tetracycline comparison results were shown in Table 4. It revealed that the range of tetracycline residue in contamination samples of the current study was $2,330-2,850 \mu \mathrm{g} / \mathrm{kg}$, lower than those obtained by Narin and Supaporn from Thailand (7,180-14,060 $\mu \mathrm{g} / \mathrm{kg}$ ) [8] and more than that reported in Refs. [5, 10].

In general, of the examined samples, $31.25 \%$ and $12.50 \%$ had these oxytetracycline and tetracycline residues, respectively. It was observed that the 
Table 2 Results of tetracycline and oxytetracycline residues analysis from different honey samples.

\begin{tabular}{|c|c|c|c|c|}
\hline \multirow[t]{2}{*}{ No. } & \multirow[t]{2}{*}{ Honey types } & \multirow{2}{*}{ Country (origin) } & \multicolumn{2}{|c|}{$\begin{array}{c}\text { Average concentration } \\
(\mu \mathrm{g} / \mathrm{kg})(\text { mean } \pm \mathrm{SD})\end{array}$} \\
\hline & & & Tetracycline & Oxytetracycline \\
\hline \multicolumn{5}{|c|}{ Honey imported samples } \\
\hline 1 & Pure bees honey & Germany & ND & $3,610 \pm 0.036$ \\
\hline 2 & Black forest honey & Germany & ND & $13,800 \pm 0.265$ \\
\hline 3 & Kashmiri honey imported by Yemen & India & ND & $9,033 \pm 0.058$ \\
\hline 4 & Kashmiri honey imported by Saudi Arabia & India & ND & $3,430 \pm 0.006$ \\
\hline 5 & Nutrition honey & Australia & ND & ND \\
\hline 6 & Kashmiri honey imported by Galap Co. & India & ND & ND \\
\hline 7 & Tropical plants honey & Thailand & ND & ND \\
\hline 8 & Black bean honey & Egypt & ND & ND \\
\hline 9 & Bashaori honey & Pakistan & $2,330 \pm 0.000$ & ND \\
\hline \multicolumn{5}{|c|}{ Locally produced honey } \\
\hline 10 & Acacia tortilihoney, Dowan & Hadramout, Yemen & ND & ND \\
\hline 11 & Sidr honey (Zizyphusspina-christi), Dowan & Hadramout, Yemen & ND & ND \\
\hline 12 & Sider honey (Zizyphusspina-christi), Jardan & Shabwa, Yemen & ND & $7,140 \pm 0.000$ \\
\hline 13 & Osaimi sider honey (Zizyphusspina-christi), Omran & Sana'a, Yemen & ND & ND \\
\hline 14 & Soctotra honey & Soctotra, Yemen & ND & ND \\
\hline 15 & Marai honey, Lowder & Abyan, Yemen & $2,850 \pm 0.000$ & ND \\
\hline 16 & Sider honey (Zizyphusspina-christi), Radfan & Lahij, Yemen & ND & ND \\
\hline \multicolumn{3}{|c|}{ Least significant difference (LSD) } & 0.000 & 0.162 \\
\hline
\end{tabular}

ND: not detected.

Table 3 Comparison of oxytetracycline residue in honey samples between the present study and other countries.

\begin{tabular}{|c|c|c|c|c|}
\hline Country & Author and year & Analysis methods & Contamination percent & Range $(\mu \mathrm{g} / \mathrm{kg})$ \\
\hline Greece & Saridaki-Papakonstadinou et al., 2006 [5] & HPLC & $14.30 \%$ & $23.00-335.00$ \\
\hline India (imported) & Jonson and Jadon, 2010 [7] & HPLC-FLD & $50.00 \%$ & $27.10-250.40$ \\
\hline Thailand & Narin and Supaporn, $2010[8]$ & HPLC-FLD & $66.66 \%$ & $60,150-106,900$ \\
\hline Iran & Mahmoudi et al., 2014 [1] & ELISA, HPLC & $23.44 \%$ & $2.10-120.60$ \\
\hline Pakistan & Muhammad Zai et al., 2013 [16] & HPLC & $7.00 \%$ & $1.12-2.13$ \\
\hline $\begin{array}{l}\text { India (produced } \\
\text { with country) }\end{array}$ & Chilumuru et al., 2015 [2] & HPLC-UV & $100.00 \%$ & $0.05-0.50$ \\
\hline Yemen (imported ) & Saleh et al., 2016 (current study) & HPLC-UV & $44.44 \%$ & $3,430-13,800$ \\
\hline $\begin{array}{l}\text { Yemen (produced } \\
\text { with country) }\end{array}$ & Saleh et al., 2016 (current study) & HPLC-UV & $14.29 \%$ & 7,140 \\
\hline
\end{tabular}

HPLC-FLD: high performance liquid chromatography with fluorescence detection; ELISA: enzyme-linked immuno-sorbent assay; HPLC-UV: HPLC with ultraviolet detector.

Table 4 Comparison of tetracycline residue in honey samples between the present study and other countries.

\begin{tabular}{llllc}
\hline Country & Author and year & Analysis methods & Contamination percent Range $(\mu \mathrm{g} / \mathrm{kg})$ \\
\hline Greece & Saridaki-Papakonstadinou et al., 2006 [5] & HPLC & $4.78 \%$ & $18-57$ \\
Thailand & Narin and Supaporn, 2010 [8] & HPLC-FLD & $33.33 \%$ & $7,180-14,060$ \\
Romania & Monica et al., 2012 [10] & ELISA & $50.00 \%$ & $15.47-60.67$ \\
$\begin{array}{l}\text { Yemen (imported ) } \\
\text { Yemen (produced } \\
\text { with country) }\end{array}$ & Saleh et al., 2016 (current study) & HPLC-UV & $11.11 \%$ & 2,330 \\
\hline
\end{tabular}


tetracycline and oxytetracycline detected in the samples studied have been reported to be more than MRLs.

\section{Conclusions}

Result showed that of the examined samples, $31.25 \%$ and $12.50 \%$ had these oxytetracycline and tetracycline residues, respectively. Therefore, the honey samples did not have the desired conditions because of presence of oxytetracycline and tetracycline residues more than MRLs. Other studies are necessary to evaluate other drug residues in honey samples and the hazards of these residues in relation with daily intakes and other related factors.

\section{References}

[1] Mahmoudi, R., Moosavy, M., Norian, R., Kazemi, S., Nadari, M., and Mardani, K. 2014. "Detection of Oxytetracycline Residues in Honey Samples Using ELISA and HPLC Methods." Pharmaceutical Sciences 19 (4): 145-50.

[2] Chilumuru, R. M. R., Lakkineni, C. A. K., and Chandra, B. S. 2015. "Quantitative Analysis of Oxytetracycline Residues in Honey by High Performance Liquid Chromatography." Int. Res. J. Biological Sci. 4 (5): 59-65.

[3] Khanbash, M. S., and Al-Kaff, H. A. 2007. "Using of Yemeni Honey in Dressing of Gluteal and Breast Abscesses." Honeybee Center, Hadhramout University, Yemen. Accessed July, 2014. http://hust.edu.oak.arvixe.com/.

[4] Center for Food Safety (CFS). 2006. "Antibiotics Found in Honey.” CFS, Hong Kong. Accessed January 5, 2013. http://www.cfs.gov.hk/eindex.html.

[5] Saridaki-Papakonstadinou, M., Andredakis, S., Burriel, A., and Tsachev, I. 2006. "Determination of Tetracycline Residues in Greek Honey.” Trakia J. of Sci. 4 (1): 33-6.

[6] Bonta, V., Marghitas, L. A., Dezmirean, D., Moise, A., Bobis, O., and Maghear, O. 2007. "Optimization of HPLC Method for Quantifying Tetracycline Residue in Honey." Bull. Uni. Agri. Sci. Veter. Med. 63-64: 186-90.
[7] Johnson, S., and Jadon, N. 2010. Antibiotic Residues in Honey. New Delhi, India: Center for Science and Environment.

[8] Narin, T., and Supaporn, S. 2010. "HPLC-Fluorescence Detection Method for Quantitative Determination of Tetracycline Antibiotic Residues in Honey." Naresuan Uni. Science J. 6 (2): 147-55.

[9] Thanasarakhan, W., Kruanetr, S., Deming, R. L., Liawruangrath, B., Wangkarn, S., and Liawruangrath, S. 2011. "Sequential Injection Spectrophotometric Determination of Tetracycline Antibiotics in Pharmaceutical Preparations and Their Residues in Honey and Milk Samples Using Yttrium (III) and Cationic Surfactant." Talanta 84 (5): 1401-9.

[10] Monica, C. C., Gabriela-Alina, D., Mirel, G., and Delia, P. 2012. "Stability of Tetracycline Residues in Honey." $J$. Serb. Chem. Soc. 77 (7): 879-86.

[11] European Union Regulation (EC) No. 396/2005-MRLs. 2013. "A Database of EU MRLs and Pesticide Authorization Status (Dir 91/414/EEC).” Accessed June 6, 2013. https://ec.europa.eu/food/safety_en.

[12] Official Journal of the European Union L152. 2009. Regulation (EC) No. 470/2009 of the European Parliament and of the Council.

[13] Official Journal of the European Union L15/1. 2010. Regulation (EU) No. 37/2010.

[14] FAO/WHO. 2008. "Codex Alimentarius: Veterinary Drugs Residues in Food.” Accessed July, 2014. http://www.fao.org/fao-who-codexalimentarius/standards /veterinary-drugs-mrls/en/.

[15] CDC. 2000. "Interagency Task Force on Antimicrobial Resistance: A Public Health Action Plan to Combat Antimicrobial Resistance." The Centers for Disease Control and Prevention, the Food and Drug Administration, and the National Institutes of Health. Accessed July 17, 2014. http://www.cdc.gov/ drugresistance/itfar/introduction_overview.html.

[16] Zai, I. U. M., Rehman, K., Hussain, A., and Shafqatullah. 2013. "Detection and Quantification of Antibiotics Residues in Honey Samples by Chromatographic Techniques." Middle-East Journal of Scientific Research 14 (5): 683-7. 